\title{
NEW THICK-FILM TEMPERATURE SENSORS APPLIED IN SOME HYBRID MEASUREMENT DEVICES
}

\author{
JANUSZ J. GONDEK and MAREK A. WÓJCICKI \\ Microelectronics Department, Institute of Electronics, Mining and Metallurgical University, ul. \\ Czarnowiejska 78, 30-054 Kraków, Poland.
}

\begin{abstract}
The present paper is devoted to the technological problems connected with the construction, the choice of pastes and substrates, the screening process and the laser or abrasive trimming involved in the production of thick-film resistance temperature sensors designed by the authors. It also gives their main functional parameters and characteristics indicating the possibility of the use of thick-film sensors not only in the measurement of temperatures, in a wide range, but also in determining the velocity and volume of flowing gases or liquids. On the basis of the relations investigated, the authors give examples of constructions of a few hybrid measurement devices for use in industry, transportation and medicine. Technical and economic aspects of the production of hybrid measurement devices are also dealt with.
\end{abstract}

\section{INTRODUCTION}

As a result of the world-wide fuel and energy crisis and the pollution of the natural environment, one can observe a growing interest in energy- and raw materials-saving technologies of production, which do not pollute our environment and which have a great facility of adaptation to the changeable conditions set by customers. These requirements are completely fulfilled by the hybrid thick-film technology. This is confirmed on the scientific side, by the rapidly growing interest in this technology shown by many researchers and teams, even those that up till now have devoted their attention to the monolithic or thin-film technology.

One of the possibilities of application of the thick-film technolgy is the production of sensors and hybrid devices for the measurement of various physical and chemical parameters. In many cases sensors, together with hybrid circuits can make one functional unit. And the following properties constitute additional reasons for their use: resistance to mechanical damage, vibrations and chemical activity of the mediums; good repeatability of parameters and low cost of production. Temperature, velocity and volume of the flow of gases and liquids are among the most important and most often measured parameters. The authors of the present paper undertook the task of showing the possibility of the use of the thick-film resistance temperature sensors, constructed by them, in certain hybrid devices for temperature, velocity and volume of flowing gases and liquids measurement.

\section{THICK-FILM TEMPERATURE SENSORS}

The principle of functioning of thick-film resistance temperature sensors is discussed by the authors in details in. ${ }^{4}$ On the basis of the researches ${ }^{2,3,4,5}$ they concluded, that for thick-film meander resistors, used in the construction of the sensor and made with the use of conductive pastes, the following general equations are satisfied: 


$$
\mathrm{R}_{\mathrm{T}}=\mathbf{R}_{\mathbf{2 7 3}}(1+\alpha \mathrm{T})
$$

$\alpha=\frac{R_{T}-R_{273}}{R_{273}(T-273)}$

where: $R_{T}, R_{273}$ - resistance at temperature $T$ and $273 \mathrm{~K}, \alpha$ - temperature coefficient of resistance TCR.

In designing the sensors the following criteria were accepted:

1) Substrate - alumina $96 \% \mathrm{Al}_{2} \mathrm{O}_{3}$ ceramic plate, with dimensions $50 \times 30 \times 0.5 \mathrm{~mm}$ and $\mathrm{R}_{\mathrm{a}}<0.9 \mu \mathrm{m}$, Polish made,

2) Construction of the resistor - meander type, with maximum use of the substrate surface.

3) The use of Du Pont conductive compositions: DP 9530, DP 9780, DP 9791. In the computation of the parameters of the meander resistors, the authors used a special computer programme, in the Fortran language, given in. ${ }^{4}$ The choice of the above enumerated pastes was made on the basis of the results of earlier research, ${ }^{2,3,4,5}$ from among seven conductive pastes produced by Du Pont and Engelhard. The decisive factor was the criterion of a temperature coefficient of resistance TCR ' as great as possible a high value of the correlation coefficient, above 0.99 and resistance to physical and chemical activity of the mediums. The technology of the production of the sensors was consistent with the description given in. ${ }^{4}$ Precise screening was used, thus making it possible to use printing conductive strips from 60 to $150 \mu \mathrm{m}$ wide. Screens were masked by means of the intermediate method, with use of the French made photosensitive material Triflex CUT-67. In order to obtain the repeatable initial resistance of the sensors, laser trimming was used. The authors concluded that abrasive trimming is not precise enough and it causes damage of the substrate, and even to the narrow resistor.

Detailed research, devoted to the constructed sensors, gave as a result their basic characteristics of relative resistance in the function of temperature $R_{T} / R_{273}=f(T)$, shown in Figure 1 and the main parameters, given in Table I.

It can be observed that the most sensitive sensors are those made with the use of DP 9530 paste, but they are suitable only for low temperatures. On the other hand, sensors made of pastes DP 9780 and DP 9791 are suitable for high temperatures. In the measurement of temperature, in order to avoid the phenomenon of self-heating, one should limit the current of the sensor to the value I $<5 \mathrm{~mA}$.

The possibility of work in a wide range of temperatures and obtaining good parameters of use are confirmed by the data in the literature..$^{8,9,11}$

\section{THICK-FILM SENSORS IN HYBRID DEVICES FOR TEMPERATURE MEASUREMENT}

Resistance thick-film sensors exhibit a definite advantage, over other kinds of temperature sensors, thanks to their linear and repeatable characteristic in a broad range of temperatures and on inexpensive and flexible technology, which allows the accommodation of their shape and size to the demands of the customer. Thanks to this, they can be easily used in measurement devices and automatic control systems without making use of the complicated linearization networks. ${ }^{10}$

Examples of hybridized devices for measuring and regulating temperature, designed by the authors, are given below. 


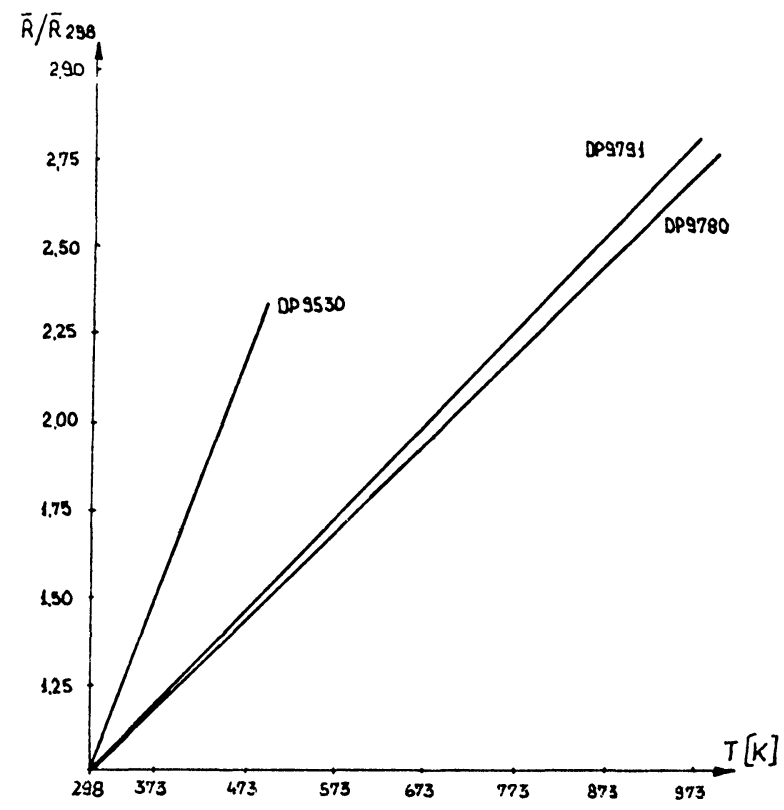

FIGURE 1 The basic characteristics of relative resistance for thick-film temperature sensors.

Figure 2 gives a circuit diagram of the hybrid device for measuring temperature in research laboratories, industry and medicine. For supplying the measuring bridge, a hybrid D.V. source, type AV-1, Polish made was used. For the amplification of the output signal of the unbalance of the bridge, operational amplifier $\mu \mathrm{A} 741$ was chosen, from which the signal is sent to the $\mathrm{V} / \mathrm{F}$ converter, type GMC-018, Polish made. The converter converts output voltage from the amplifier into a frequency, which after passing through the main gate, opened to $20 \mathrm{~ms}$, is counted by the counters and then written in the registers, decoded and displayed. Next the counters are erased and the measuring cycle is repeated. The number of impulses counted by the counters is proportional to the temperature of the medium in which the sensor is placed. The broken line denotes hybrid microcircuits which are part of the measuring device. Such a construction increases the reliability of device, makes possible an easy replacement of a damaged hybrid and connecting hybrids in various ways. Thanks to this, it is possible to fix the first two hybrids near the sensor and the remaining, digital part of the device - at a greater distance, which eliminates the influence of interference and of the length of leads connecting the place of measurement with the place of information reception.

TABLE I

Main parameters of thick-film temperature sensors

\begin{tabular}{lllll}
\hline & $\begin{array}{l}\text { Range of } \\
\text { temperatures } \\
{[\mathrm{K}]}\end{array}$ & $-\frac{\mathbf{R}_{\mathbf{3 7 3}}}{\mathbf{R}_{\mathbf{2 7 3}}}$ & $\begin{array}{l}\text { Sensitivity } \\
{[\mathrm{ppm} / \mathrm{K}]}\end{array}$ & $\begin{array}{l}\text { Thermal time } \\
\text { constant } \\
{[\mathrm{s}]}\end{array}$ \\
\hline Paste & $273-973$ & 1.280 & 2807 & 1.2 \\
DP 9790 & $273-973$ & 1.285 & 2840 & 1.2 \\
DP 9530 & $223-473$ & 1.555 & 6445 & 1.2 \\
\hline
\end{tabular}




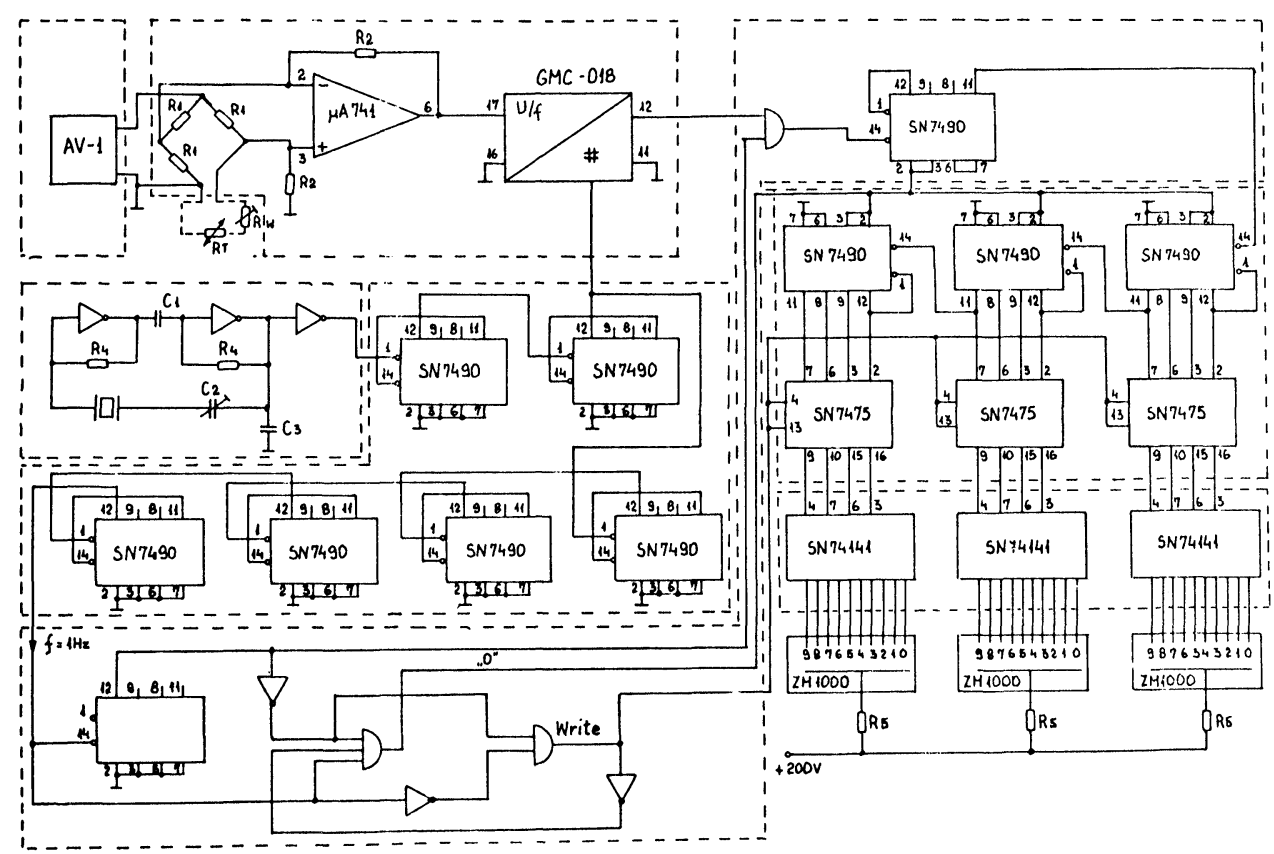

FIGURE 2 The circuit diagram of the hybridized temperature measurement dev.

Figure 3, on the other hand, represents an applicational hybrid microcircuit designed for thick-film temperature sensors installated in a car. ${ }^{6}$ The microcircuit is based on the use two monolithic microcircuit UL1111N type and five transistor p-n-p chips. It satisfies the following measurement and automatic control functions:

1) Circuit for measuring temperature of water cooling the engine $-R_{T 3}$ - sensor, $\mathrm{A}_{1}$ - indicator, $\mathrm{L}_{1}$ - alarm lamp. lamp.

2) Circuit for measuring oil temperature $-R_{T 4}-$ sensor, $A_{2}$ - indicator, $L_{2}$ - alarm

3) Air conditioning automatic circuit $-R_{T 1}, R_{T 2}$ - sensors of limit temperatures, $\mathrm{K}_{5}$ - "summer-winter" switch, $\mathrm{K}_{4}, \mathrm{H}_{1}, \mathrm{~F}_{2}$ - switch, heater and rear window blower, $\mathrm{K}_{3}, \mathrm{~F}_{1}$ - switch and main blower, $\mathrm{K}_{2}, \mathrm{~L}_{4}$ - master switch and air conditioning circuit signal lamp.

4) Brake lining temperature alarm circuit $-R_{T 5}$ - sensor, $L_{3}-$ alarm lamp.

5) Road icing alarm circuit $T<275 \mathrm{~K}-\mathrm{R}_{\mathrm{T} 6}$ - sensor, $\mathrm{L}_{4}$ - alarm lamp.

Figure 3 also represents the following two items; ignition switch $K_{1}$ and adjustable potentiometers of limiting function thresholds $R_{1} \div R_{6}$ for particular circuits.

\section{THERMOCONDUCTOMETRIC FLOW SENSORS}

If the current passing through a resistance temperature sensor is great, $I \gg 5 \mathrm{~mA}$, it brings about its cooling. As a result of this, the temperature and, at the same time, the resistance of the sensor are fixed. The flow of gas or liquid causes intensified cooling of the sensor and a new state of balance at temperature and resistance. Making use of the phenomenon 


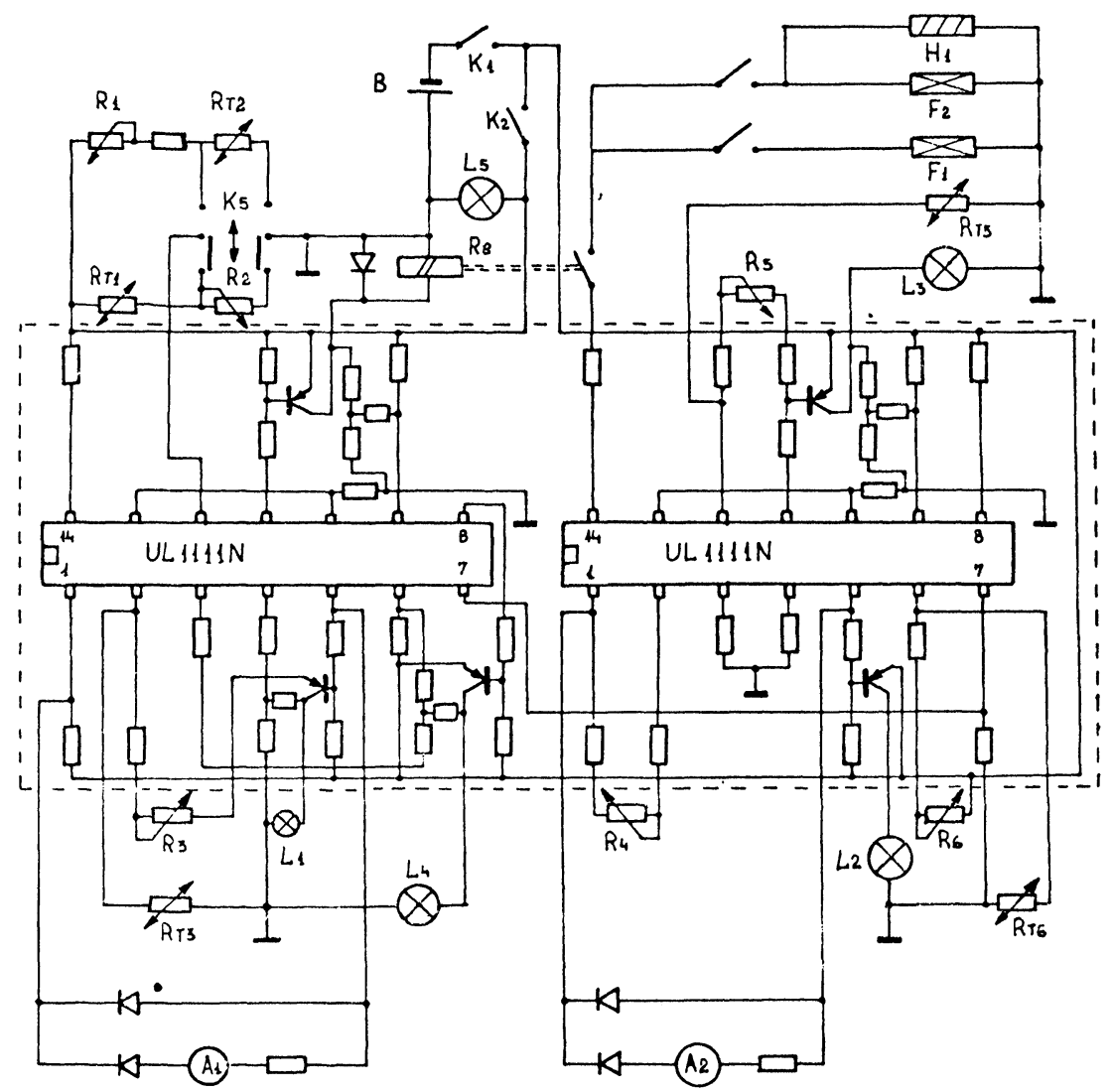

FIGURE 3 The circuit diagram of the applicational hybrid microcircuit for car thick-film temperature sensors.

one can obtain a thermoconductometric velocity sensor for flowing gases or liquids. The relation between the resistance of the sensor and the velocity of flowing medium, in a steady state, can be described by means of the equation: ${ }^{7}$

$R_{T}=R_{273} \frac{1(\lambda+A \sqrt{ } w)}{1(\lambda+A \sqrt{ } w)-\alpha I^{2} R_{273}}$

where: 1 - length of resistor, $\lambda$ - thermal conductivity of medium, A - material and constructional constant, $w$ - velocity of flowing medium.

As one can observe, the relation is expressed by means of a complicated mathematical function and therefore in practice it is easier to determine it experimentally. The three kinds of the thick-film thermoresistor described above were subjected to testing in a wind tunnel, in which a variable flow of air with the constant temperature $298 \mathrm{~K}$ was obtained. The measurement of the velocity of flowing air was done with the use of PitotPrandtl's method. The thermoresistors were supplied with D.V. chosen so that one could obtain the temperature of the plate 323,343 or $373 \mathrm{~K}$ stationary air with temperature $298 \mathrm{~K}$. The value of current passing through the sensor was measured at different velocities of flowing air. 


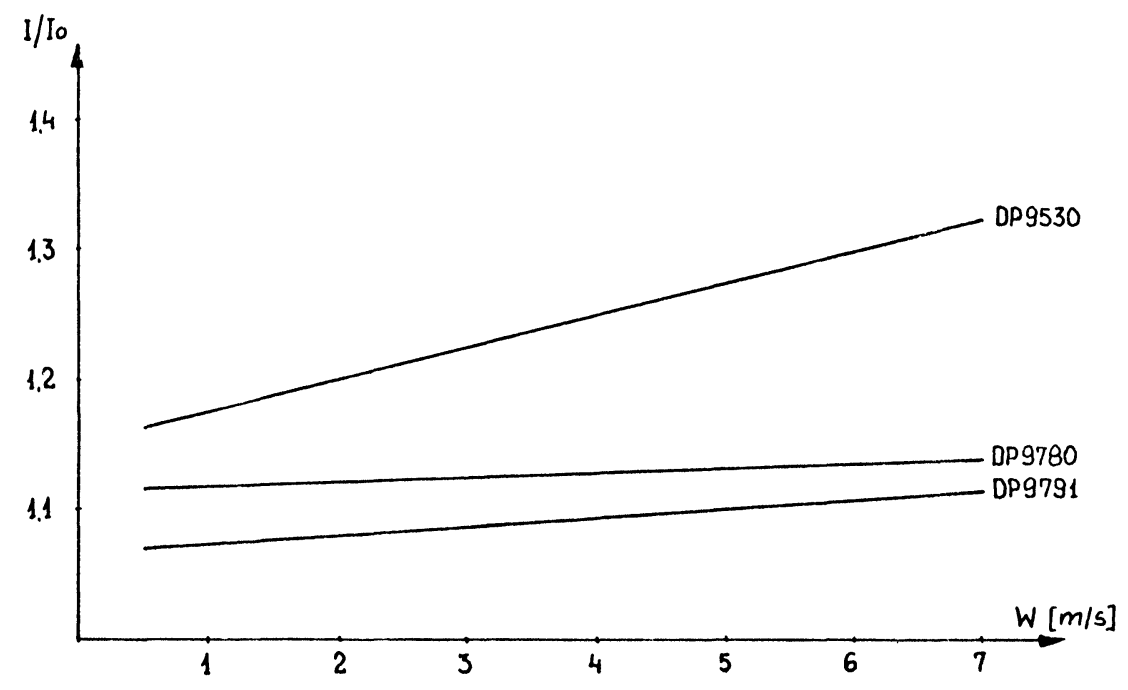

FIGURE 4 The relative current characteristics of thermoconductive flow sensors made by using DP 9530, DP 9780 and DP 9791 compositions.

Figure 4 represents the relation between relative current for three kinds of sensors and the velocity of flowing air. The temperature of them in stationary conditions was $373 \mathrm{~K}$. One can see that the greatest sensitivity is possessed by the sensor made with the use of DP 9530 paste. In order to determine the influence of the temperature on its sensitivity, the following characteristics were determined: relative current - air velocity for three temperatures 323, 343 and $373 \mathrm{~K}$, resistor made with DP 9530 paste, Figure 5. An increase of 3.42 times in the sensitivity of the sensor was obtained at the increase of its temperature from 323 to $373 \mathrm{~K}$. (Figure 5). The possibility for such construction of the sensor is confirmed by similar solutions described in the literature. ${ }^{1}$

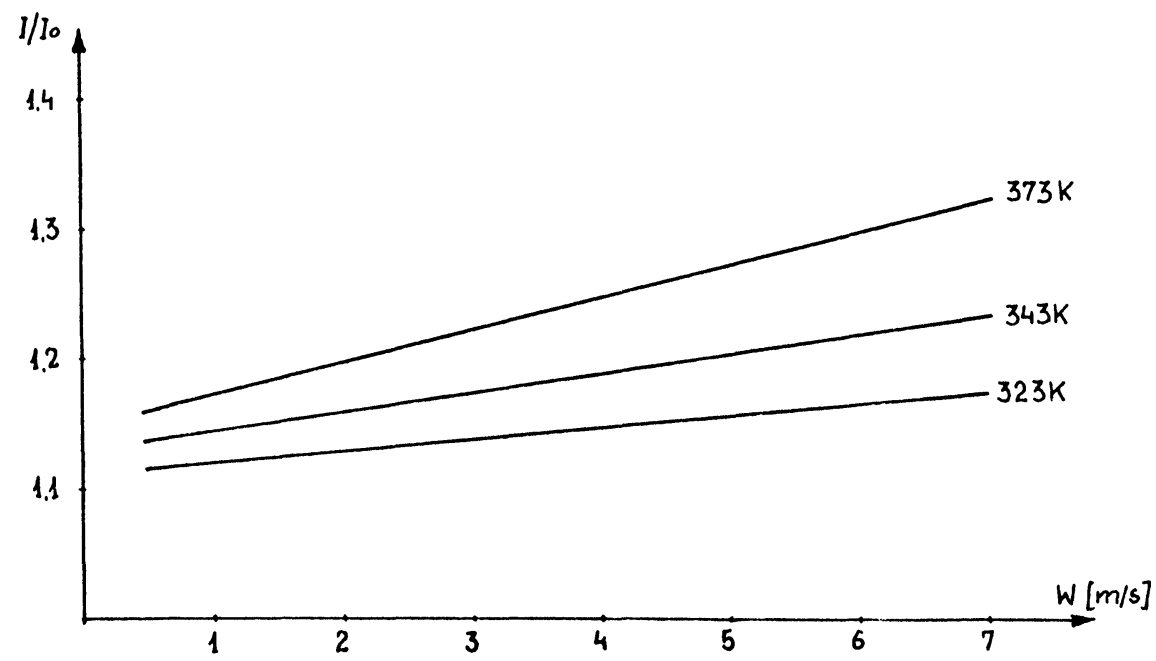

FIGURE 5 The relative current characteristics of thermoconductive flow sensors made with the use DP 9530 paste at various temperatures of the plates. 


\section{THICK-FILM THERMORESISTORS IN HYBRID MICROCIRCUITS FOR MEASURING VELOCITY AND VOLUME OF FLOWING GASES AND LIQUIDS}

Measurement of velocity of flowing gases and liquids is done in a D.C. bridge containing a sensor. What is measured is the current on a diagonal of the bridge, or the value of current supplying the bridge, or the voltage drop on an additional resistor connected in series with the bridge. Calibration of the measuring device is done directly in $[\mathrm{m} / \mathrm{s}]$, in the medium in which the sensor will function. The easiest way to provide for temperature compensation is to include-in the arm of the bridge opposite the sensor - an identical thermoresistor placed in the same medium but in the stationary state. Figure 6 represents a circuit diagram of a bridge hybrid micro-circuit, with a thick-film resistor $R_{T}$, for measuring velocity of flowing medium. Using the simple formula for the volume of flowing medium $\mathrm{Q}$ :

$Q=s \int_{0}^{t} w d t$

where: $s$ - constant cross-section area of flow, $w$ - variable velocity of flow, $t$ - time, one can, for a constant cross-section area of the pipe in which the sensor is placed and, moreover, using a simple electronic integrating circuit, obtain a device for measuring the volume of the flowing medium.

\section{CONCLUSIONS}

On the basis of the study of relevant literature and their own research, the authors found that the designed thick-film thermoresistors in hybrid microcircuits are fully usable in measuring temperature as well as velocity and volume of flowing gases and liquids. Thanks to their inexpensive technology of production, repeatability of parameters, linearity of characteristics, resistance to physical and chemical influence of the medium

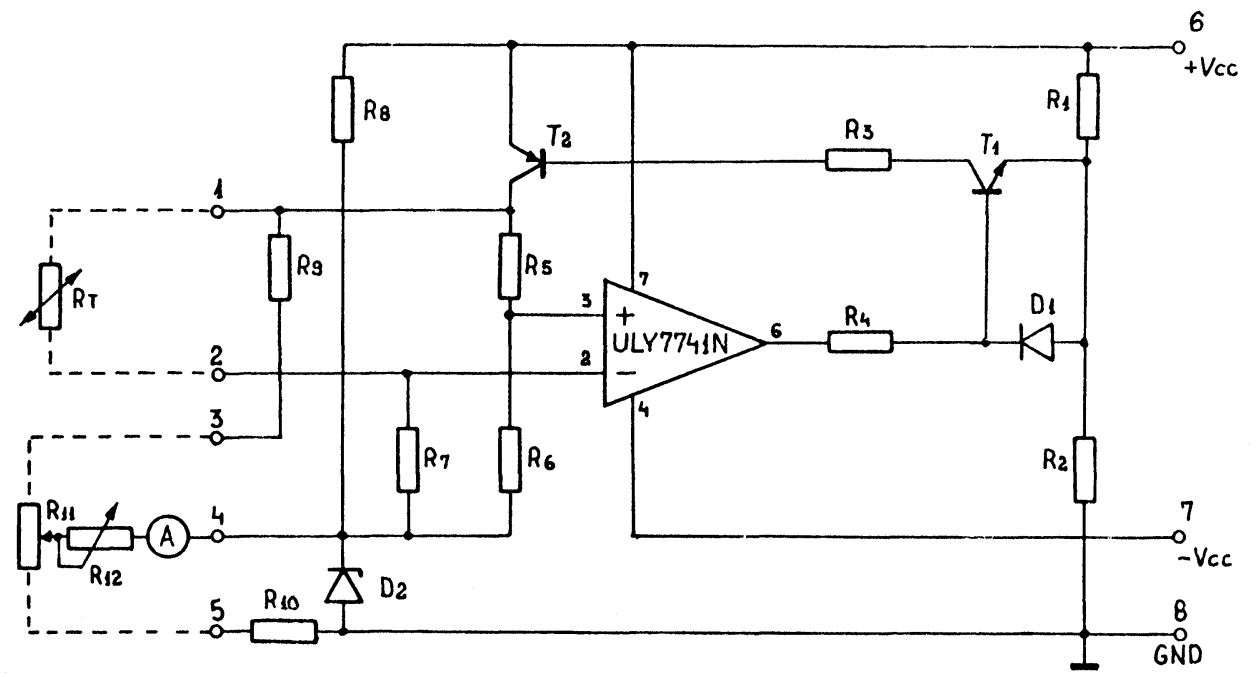

FIGURE 6 The circuit diagram of the hybrid device for measuring velocity of flowing medium, with thick-film sensor. 
and easy adaptation to demands of customers, they are universally applicable in industry, medicine and transportation. Improvement of the parameters will be possible by the choice of special substrates, a change of dimensions and topology, and the use of appropriate protective materials.

\section{ACKNOWLEDGEMENTS}

The authors of the paper would like to express gratitude to their wives Wanda and Małgorzata and to Mr. L. Maslanka and M. Maj for their valuable help during research.

\section{REFERENCES}

1. DISA, Probe Manual, (Copenhagen, Denmark, 1976).

2. Gondek, J., Krajewski, G., Wojcicki, M., "Grubowarstwowy rezystancyjny czujnik temperatury", II Konferencja Technika Hybrydowa w Elektronizacji Kraju, Studia-Informacje-Przyczynki, PIE, Warszawa, Polska, 1980.

3. Gondek, J., Krajewski, G., Wojcicki, M., "Wytwarzanie rezystancyjnych przetworników temperatury przy uzyciu past przewodzacych", Konferencja Miedzynarodowa MIKROELEKTRONIKA 80, Torun, Polska, 1980.

4. Gondek, J., Wojcicki, M., New Du Pont compositions applied in thick-film temperature and humidity sensors, Proceedings of IMC-80 Conference, Tokyo, Japan, 1980.

5. Gondek, J., Krajewski, G., Wojcicki, M., Grubowarstwowe czujniki temperatury, Materialy I Konferencji Naukowej Technologia Elektronowa ELTE-80, Wroclaw-Karpacz, Polska, 1980.

6. Konopinski, M., Elektronika w technice motoryzacyjnej, (WKL, Warszawa, Polska, 1979).

7. Lapinski, M., Wlordarski, W., Miernictwo elektryczne wielkos'ci nieelektrycznych, WNT, Warszawa, Polska, 1968.

8. Matthey Electronics, Thermafilm 100 W 47, Stoke-on-Trent, England, January 1976.

9. Micro-Measurements, Bondable temperature sensors, TN-0140-3, USA, 1976.

10. Renneberg, M., "Trends in thermometry", Electron, (20 March 1979).

11. Rosemount Eng. Co. Ltd., "Platfilm temperature detectors", Bulletin E10-007, (Bognor Regis, England, 1977). 

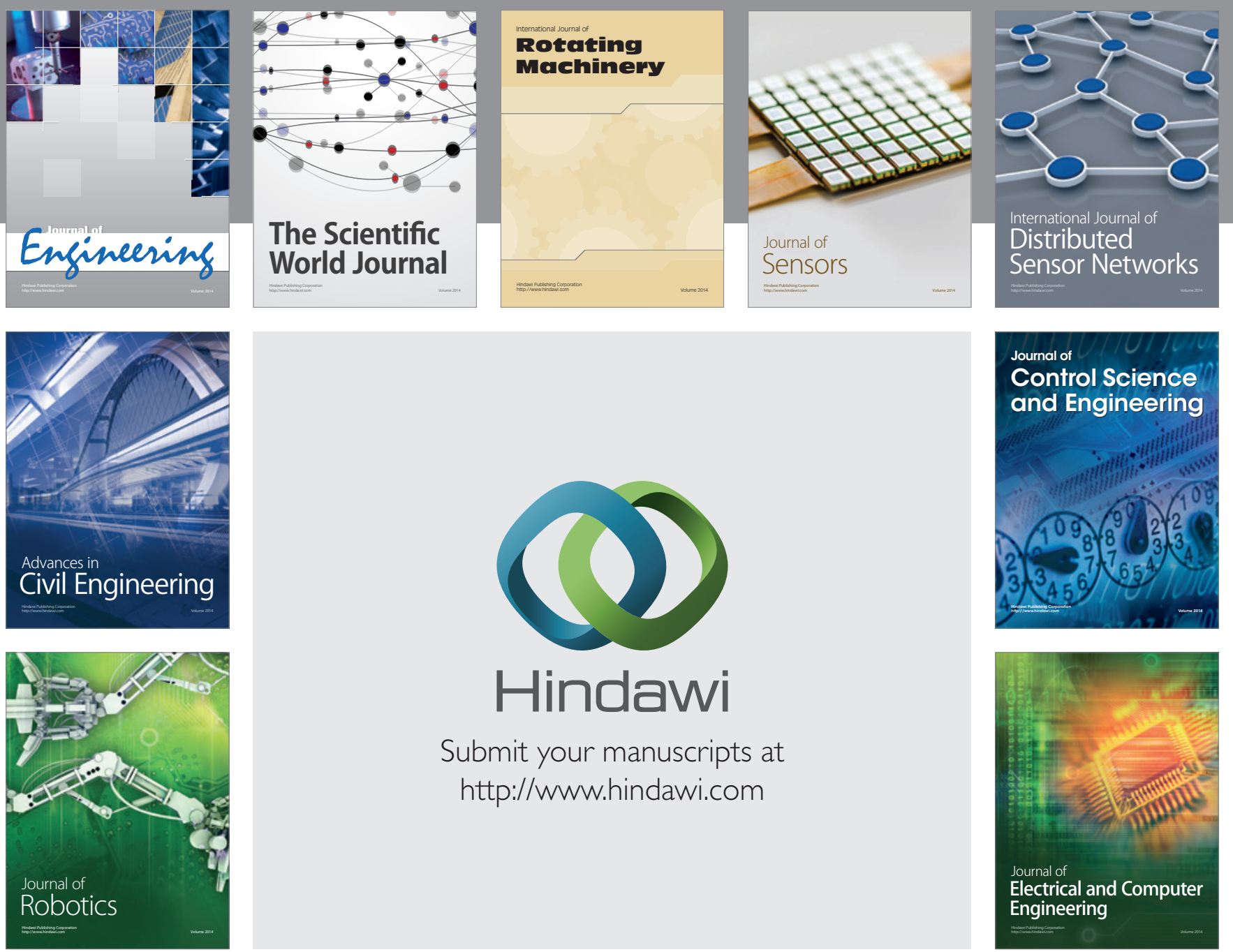

Submit your manuscripts at

http://www.hindawi.com
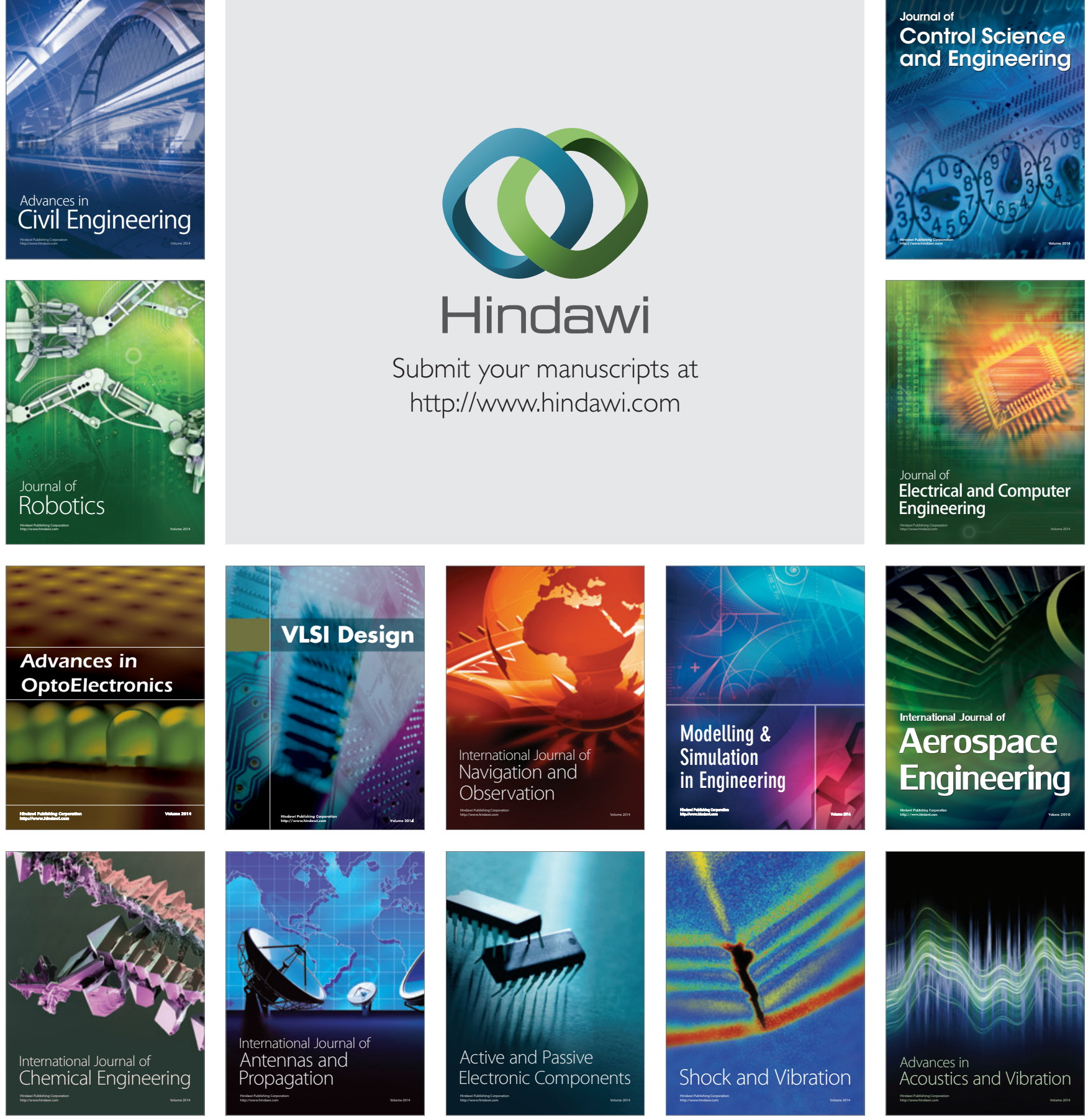